\title{
IDENTIDADE, CULTURA E SEGURANÇA ALIMENTAR: \\ CONTRADIÇÕES NA PRODUÇÃO DA QUINOA REAL EM \\ COMUNIDADES TRADICIONAIS DE SALINAS DE GARCI DE \\ MENDOZA, NO ALTIPLANO BOLIVIANO ${ }^{1}$
}

\author{
Brigida Choquehuanca Laura ${ }^{2}$ \\ Romilda de Souza Lima ${ }^{3}$ \\ Alberto Feiden ${ }^{4}$
}

\begin{abstract}
Resumo: Este artigo trata sobre a comunidade camponesa tradicional Salinas de Garci de Mendoza, no altiplano boliviano. O foco principal está nas mudanças pelas quais passa o modelo produtivo, bem como as implicações na segurança e soberania alimentar da região e do país, que é considerado o principal produtor e exportador da variedade "quinoa real". Efetivou-se uma pesquisa de campo na comunidade entre os meses de março e abril de 2018, temporada da colheita da quinoa. Foram realizadas entrevistas com produtores da "quinoa real", técnicos e lideranças da comunidade. Os resultados evidenciam que a quinoa passou de um sistema tradicional de produção a um sistema de monocultivo, onde o capital e a maquinaria agrícola entram como novo elemento imperante na comunidade. Culturalmente a quinoa cumpria um significado importante na segurança e soberania alimentar da região, porém o que se observa é que grande parte dos produtores chegaram a cultivar, exclusivamente, com o propósito de destinar a totalidade da produção ao mercado e não para o autoconsumo, ocasionando interferência nos hábitos alimentares dos locais.
\end{abstract}

Palavras Chaves: Segurança; Soberania alimentar, Quinoa real, Agricultura, Comunidade.

\section{IDENTITY, CULTURE AND FOOD SECURITY: CONTRADICTIONS IN ROYAL QUINOA PRODUCTION IN TRADITIONAL COMMUNITIES FROM SALINAS DE GARCI MENDOZA, IN THE BOLIVIAN ALTIPLANO.}

\begin{abstract}
This paper, result from a master's degree research, presents in a summarized a reality lived in the traditional farming community Salinas de Garci de Mendoza, in the bolivian altiplano, focusing mainly in the changes that are currently in the production model, and the consequences for security and sovereignty feed the region of the country, which is considered the main producer and exporter of the variety of "real quinoa". A field research was carried at the community in the town of Salinas between march/april of 2018, during the quinoa harvest season. Interviews were made with royal quinoa farmers, technical assistants and community leader-representatives. The
\end{abstract}

\footnotetext{
${ }^{1}$ Este artigo corresponde à pesquisa de dissertação de mestrado da primeira autora, defendida em 2019, com recurso de bolsa de pós-graduação pela Coordenação de Aperfeiçoamento de Pessoal de Nível Superior (CAPES).

${ }^{2}$ Bacharel em Desenvolvimento Rural e Segurança Alimentar pela UNILA. Mestre em Desenvolvimento Rural Sustentável, pela UNIOESTE https://orcid.org/0000-0002-6006-9398 Email: cbrilaura25@ gmail.com

${ }^{3}$ Professora Adjunta na Universidade Estadual do Oeste do Paraná - UNIOESTE, campus de Francisco Beltrão, Departamento de Nutrição. Professora Permanente no Programa de Pós-Graduação em Desenvolvimento Rural Sustentável, da UNIOESTE, campus de Marechal Cândido Rondon. Integra a Rede Nacional de Pesquisa em Segurança Alimentar e Nutricional e o Grupo de Pesquisa em Segurança Alimentar (Gepsa) - UNIOESTE. Email: romislima2@gmail.com Orcid: https://orcid.org/0000-0002-0968-0044

${ }^{4}$ Pesquisador A da Empresa Brasileira de Pesquisa Agropecuária - EMBRAPA. Pesquisador do Programa de PósGraduação em Desenvolvimento Rural Sustentável, da UNIOESTE, campus de Marechal Cândido Rondon (Convenio Embrapa/Unioeste). Integra o Grupo de Pesquisa em Grupo Interdisciplinar e Interinstitucional de Pesquisa e Extensão em Desenvolvimento Sustentável (Unioeste). Orcid: https://orcid.org/0000-0001-8951-825X Email: 
results show that quinoa has gone from a traditional farming system to an monoculture system, where the agricultural capital and machinery become a new leading element in the community. Culturally quinoa has always an important meaning in food security and sovereignty in the region, however, it was observed that a large part two of the farmers worked, exclusively, with the intention to destine the production to the market, not for eating and, consequently, modifying two farmers' eating habits.

Keywords: Food security; Food sovereignty, Real quinoa, Agriculture, Community.

\title{
IDENTIDAD, CULTURA Y SEGURIDAD ALIMENTARIA: CONTRADICCIONES EN LA PRODUCCIÓN DE QUINUA REAL EN COMUNIDADES TRADICIONALES DE SALINAS DE GARCI MENDOZA, EN EL ALTIPLANO BOLIVIANO.
}

\begin{abstract}
Resumen: Este artículo se refiere a la tradicional comunidad campesina Salinas de García de Mendoza, en el altiplano boliviano. El foco principal está en los cambios que está atravesando el modelo productivo, así como las implicaciones para la seguridad y soberanía alimentaria en la región y el país, considerado el principal productor y exportador de la variedad "quinua real". Se realizó un relevamiento de campo en la comunidad entre marzo y abril de 2018, época de cosecha de quinua. Se realizaron entrevistas con productores, técnicos y líderes comunitarios de "quinua real". Los resultados muestran que la quinua pasó de un sistema de producción tradicional a un sistema de monocultivo, donde el capital y la maquinaria agrícola ingresan como un nuevo elemento en la comunidad. Culturalmente, la quinua jugó un papel importante en la seguridad y soberanía alimentaria de la región, pero lo que se observa es que gran parte de los productores vinieron a producir, exclusivamente, con el propósito de destinar toda la producción al mercado y no a lo propio consumo, provocando interferencias en los hábitos alimentarios de los lugareños.

Palabras Clave: Seguridad alimentaria, Soberanía alimentaria, Quinua Real, Agricultura, Comunidad.
\end{abstract}

\section{Introdução}

O presente artigo aborda sobre a produção da quinoa no contexto da segurança e soberania alimentar, a partir de um estudo na comunidade Salinas de Garci Mendoza, Altiplano Sul da Bolívia, com pesquisa de campo realizada entre os meses de março e abril de 2018 , temporada da colheita da quinoa. A coleta de informações foi realizada por meio de entrevistas com produtores da "quinoa real", assistentes técnicos, autoridades originárias e lideranças-representantes da comunidade. Obtiveram-se dados empíricos mediante aplicação de entrevista semiestruturada, possibilitando, assim, contrastar as infomações com a literatura sobre o assuto. Portanto, a pesquisa realizada teve o objetivo de analisar e salientar o impacto da nova lógica produtiva da quinoa na segurança e soberania alimentar, fundamentado de uma realidade experienciada na comunidade tradicional do Município Salinas de Garci Mendoza (Salinas), Altiplano Sul, considerada como o principal produtor da "Quinoa Real". Da forma semelhante, abordam-se as consequências da demanda repentina pela quinoa, no mercado local, interno e externo.

A quinoa (Chenopodium Quinoa Wild),é um grão, denominado como um pseudocereal. O termo "pseudo" é utilizado em função de ser uma semente com amido, mas que não pertence à classe dos cereais e não contém glúten; "se assemelham aos cereais por apresentarem uma 
proporção aproximada em carboidratos, lipídeos, proteínas e fibras comparado ao trigo" (SILVA; SOUZA; GULARTE, 2015). Trata-se de um alimento de alto valor nutritivo e importante para a segurança alimentar e nutricional. Tanto assim que, em 2013, a Organização das Nações Unidas para Agricultura e Alimentação (FAO) determinou como sendo o ano internacional da quinoa.

Sua domesticação se deu há milhares de anos pelos povos andinos da América do Sul. O pseudocereal milenar era concebido como alimento primordial nas culturas andinas muito antes da colonização espanhola-europeia. A produção da "chenopodium quinoa wild" foi adaptada a climas extremos, como o Altiplano, região com baixa precipitação, e encontra-se a 3600 metros acima do nível do mar. O clima influencia e restringe a biodiversidade nesse ecossistema.

Nos últimos anos, a produção da quinoa foi expandida em diferentes partes do mundo por ser um pseudocereal que consegue adaptar-se em diferentes pisos ecológicos para seu plantio. Conforme a Bioversity International, FAO, PROINPA, INIAF y FIDA (2013), a quinoa consegue adaptar-se a climas de desertos quentes e secos. A mesma pesquisa constata a sua qualidade nutritiva representada pela sua composição de aminoácidos essenciais tanto em qualidade como em quantidade, que faz desse, um alimento funcional e ideal para o organismo.

Existe uma diversidade de possibilidades de preparo tradicional do grão na alimentação e em inovações industriais. Segundo documento da FAO $(\mathrm{S} / \mathrm{d})^{5}-$ e o observado na pesquisa de campo - na alimentação, a forma mais tradiconal é consumí-lo na forma de farinha, depois de passar pelo processo de torra, e assim ser usado para fabricar pães ou no preparo de sopas. Pode também ser consumidos como cereal misturado ao leite, ou em saladas, no preparo com o macarrão, e ainda na fermentação para cerveja ou chicha, que é a bebida tradicional andina.

Segundo a investigação do Instituto Interamericano de Cooperação para a Agricultura IICA (2015), até a década de 1980, a quinoa esteve confinada aos países andinos, sendo Bolívia e Peru os principais produtores. No entanto, seu cultivo ampliou-se a América do Norte e Europa primeiro, e depois para o resto do mundo.

Foi quando começaram a ser divulgados os riquíssimos valores nutricionais que o cereal oferece, também as diferentes propriedades que contém para combater doenças no organismo humano. Orientando ao surgimento de novos interesses para adaptar e produzir em outras partes do planeta e destacando a importância da transformação na indústria de alimentos; mas, também nas indústrias farmacêuticas, químicas e cosméticas.

\footnotetext{
${ }^{5}$ http://www.fao.org/quinoa/en/
} 
Por um lado, a quinoa vem sendo considerado, na provisão alimentar, como um alimento oportuno para o combate da fome no mundo. Alguns países o adotaram como um pseudocereal estratégico para a segurança alimentar das presentes e das futuras gerações, primordialmente aqueles que sofrem com a insegurança alimentar nutritiva de forma crônica.

Por outro lado, atraído pelo seu valor e impacto econômico, muitos países visaram sua produção para fins comerciais. A pesquisa do Instituto para o Desenvolvimento Rural de Sul América (IPDRS, 2013), cita que "o interesse da Austrália, Canada, China, Holanda, França, Estados Unidos, Argentina, Peru e Equador está relacionado à comercialização. Já o interesse dos países, como Tibet (na China), Paquistão, Palestina, Marrocos e Turquia está relacionado à segurança alimentar de suas futuras gerações”. Também, as plantações em áreas tropicais, caso das savanas brasileiras, foram obtidos rendimentos mais elevados do que os da Região Andina. Atualmente, mais de 60 países estão cultivando ou avaliando a adaptação da quinoa (RISI e ROJAS, 2013, p. 30). Desta maneira, nas últimas décadas, a quinoa, que era um alimento primordial dos povos andinos - indígenas, passou a ser um alimento valorizado e estratégico do setor agrícola produtivo em diferentes regiões do mundo.

Na Bolívia existe a preservação de uma grande diversidade de espécies da quinoa, calculase entre 3 mil variedades ou ecotipos. Entre as mais conhecidas é a "quinoa real", que é uma variedade cujo grão é grande. Essa variedade é cultivada unicamente nas terras áridas e salinas do Altiplano Sul da Bolívia, nos departamentos de Oruro e Potosí (em torno dos Salares de Uyuni, Coipasa e Pastos Grandes). Outras variedades da quinoa, como a selvagem e a variedade doce, com grãos menores, são cultivadas em outras áreas das terras altas e baixas de outras regiões da Bolívia (MEJÍA, 2013, p. 28).

Nativa da Bolívia, a quinoa real é produzida nas veredas das grandes áreas salinas, também é conhecida e mais valorizada no mercado pelo tamanho e a qualidade nutricional. Salientando que, “até o momento, a variedade Quinoa Real conquistou reconhecimento da denominação de origem, e procedente, unicamente da Bolívia e do Altiplano Sul”6 (NOGALES et al., 2015, p. 16).

A quinoa foi ganhando popularidade desde o final da década de 1960 quando se implementaram políticas que permitiram sua inserção no mercado. Por ser um cereal nativo de consumo indígena andino, era pouco conhecido e consumido pela população dos grandes centros urbanos. A quantidade produzida nas comunidades camponesas indígenas era basicamente para consumo familiar. No ano de 1980, as organizações do Altiplano Sul para a economia agrícola da

\footnotetext{
${ }^{6}$ A denominação de origem correspondente à Quinoa Real foi acordada através de gestão com a Comunidade Andina de Nações. Os países da Bolívia, Colômbia, Peru e Equador acordaram reconhecer a origem da Quinoa Real como estritamente boliviano e não usar esta categorização para comercializar outras variedades do grão (NOGALES et al, 2015).
} 
quinoa iniciaram um processo em busca de consolidar e garantir mercados de comercialização, sendo criada para isso, em 1983, a primeira Associação Nacional de Produtores da Quinoa ANAPQUI, estabelecida como empresa exportadora da quinoa orgânica e de seus produtos derivados.

A FAO enquanto organização internacional para a alimentação e agricultura fornece apoio, fundamentalmente, na divulgação dos valores proteicos da quinoa em vista de um número exorbitante da população no mundo que sofre a insegurança alimentar e baixo consumo de alimentos com propriedades nutritivas importantes para a saúde. "Uma das culturas promissoras da humanidade, não apenas por suas grandes propriedades benéficas e seus múltiplos usos, mas também considerada como uma alternativa para resolver os graves problemas da nutrição humana" (BOJANIC, 2011, p. 02).

A partir do marketing, a percepção da quinoa como o alimento do futuro foi crescendo, também transcendendo na transformação do cereal para componentes dos produtos farmacêuticos, produtos cosméticos, entre outros. De maneira semelhante o preço do grão foi incrementado de forma acelerada, principalmente no mercado internacional.

Nesse contexto, os produtores originários do Altiplano Sul da Bolívia, foram motivados na especialização da quinoa, uma região onde historicamente concentraram sociedades tradicionais dos povos indígenas originários dos Aymaras e Quechuas. São povos nativos que mantiveram ao longo dos séculos uma organização sociopolítica com normativas próprias de controle territorial, como a estrutura e uso das terras comunais ou colectivas.

A "Quinoa real" unicamente produzida no Altiplano Sul boliviano é incorporada no mercado como a variedade mais requerida e valorizada, que incrementou o cultivo em grandes extensões nas áreas planas e fragmentou o uso das terras colectivas. Já que, posterior à especialização da quinoa, a terra cultivada e individualizada foi aumentando de forma intensificada (MEJÍA, 2013).

\section{Cultura alimentar andina, em destaque: a quinoa}

$\mathrm{Na}$ cultura alimentar andina os alimentos, geneticamente adaptados a climas extremos como o Altiplano, datam de milhares de anos. Hoje em dia muitas dessas variedades continuam sendo preservadas e cultivadas, os que mais se destacam são os tubérculos, raízes (oca, papalisa, isaño, maca) e grãos andinos (canahua, quinoa), como parte da diversidade de cultivos e produtos (DELGADO B; DELGADO Á, 2014, p.28). 
Segundo Morón (2000), os alimentos andinos possuem nutrientes muito ricos e são muito importantes na segurança alimentar e nutricional das comunidades, sobretudo as rurais. Destacam os principais nutrientes desses alimentos característicos da cultura andina:

Una cantidad importante de proteínas (quinua, qañiwa, y amaranto); un elevado contenido de proteínas y grasas (tarwi o chocho); principalmente carbohidratos (tubérculos y raíces); buenas cantidades de carotenos, como el tomate de árbol, el capuli y la arracacha, y, un buen contenido de minerales como la macha, la quinua y la qañiwa (MORÓN, 2000, sem paginação).

O autor destaca ainda outras contribuições fundamentais desses alimentos, para além da nutricional. Estão associadas à reprodução econômica e social dos povos rurais andinos haja vista que "aumentan la disponibilidad de alimentos y contribuyen a reducir las importaciones de los mismos; estimulan a las agroindustrias pequeñas y grandes, y, pueden convertirse en una importante fuente de divisas al exportar estos cultivos o sus productos derivados" (Ibdem, sem paginação.).

No que se refere à quinoa, objeto deste trabalho, sabe-se que se trata de um grão milenar, que representa um alimento básico e importante às populações andinas do Altiplano.

Segundo Mujica; Izquierdo; Marathee (2001), o território andino pode ser considerado como um dos principais centros mundiais de domesticação de plantas cultivadas, o mais sustentável e com maior diversidade genética. Os autores informam que as evidências arqueológicas, linguísticas, etnográficas e históricas sobre a quinoa são muito poucas. Porém há muitos sinais de natureza botânica e citogenêticas silvestres que sinalizam que sua domesticação e cultivo local envolveu um processo lento e que, possivelmente, as suas folhas foram introduzidas primeiramente na alimentação, e, posteriormente, o mesmo ocorreu com as suas sementes. A quinoa foi cultivada e utilizada pelas civilizações pré-hispânicas, sendo substituída pelos cereais com a chegada dos espanhóis, apesar de constituir um alimento básico da população da época”(não paginado, tradução da pesquisadora). A afirmação feita pelos autores acima reforça o quanto o processo de colonização européia nos primórdios representou um desrespeito à cultura alimentar dos povos originários das américas.

Ao longo dos séculos a quinoa foi um alimento preservado e cuidado pelas mesmas populações andinas. Porém, com o decorrer do tempo, as transformações dos modos de produção agrícola da quinoa foram mudando e atualmente é um alimento que ganhou visibilidade em diferentes mercados do mundo, interferindo na forma da alimentação e produção do grão.

Para compreender melhor as mudanças da agricultura da quinoa e o impacto no consumo, apresenta-se, nos próximos itens, a realidade atual na Bolívia. 


\title{
Desenvolvimento e produção da quinoa em nível nacional - Bolívia
}

Na região do Altiplano Sul boliviano (Oruro e Potosí), surgiram os interesses dos camponeses-produtores, conjuntamente às políticas implementadas para industrializar e ampliar economicamente a produção da variedade "Quinoa Real", região onde é unicamente produzida esse tipo de variedade da quinoa. Os estudos de Ormachea e Ramirez (2013) sobre a quinoa no Altiplano Sul, consideram que na década de 1970, a sua produção não era tão extensiva como atualmente, porque, basicamente não era um produto comercializável. As parcelas de produção eram reduzidas porque as pessoas produziam para autoconsumo.

No ano de 1978 chegaram os primeiros intermediários, que levavam ofertas de produtos não locais: farinha, açúcar, enlatados e frutas, que não eram muito conhecidos na região. A novidade despertou interesse dos moradores locais que se envolveram sem resistência nessa troca. Os termos da troca eram: três quintais ${ }^{7}$ de quinoa por um quintal de arroz ou farinha (ORMACHEA e RAMIREZ, 2013, p. 58). Ou seja: 145,8 Kg de quinoa em troca de 48,6 Kg de arroz ou farinha. Essa situação foi também relatada por um dos agricultores entrevistados.

\begin{abstract}
Quando começou o interesse comercial, o grão da Quinoa sofria preconceito da população urbana das cidades das classes altas-brancas do país, considerando como a "comida do índio", de forma pejorativa e marginal. Mas a iniciativa para fomentar a comercialização não se detinha, seja por dinheiro que somente chegava a um preço mesquinho ou, principalmente, na troca da quinoa por outro produto alimentar não produzido localmente (Conversa com um produtor "A", de quinoa real, do município Salinas Garcí Mendoza, associado à Associação Nacional de Produtores da Quinoa - ANAPQUI, pesquisa de campo, 2018, tradução da pesquisadora).
\end{abstract}

Dessa forma, os produtores foram enxergando uma oportunidade na produção de quinoa o incremento da produção e, a ampliação da fronteira agrícola "quinoa" não se estagnaria no altiplano da Bolívia, passando de 20.000 hectares a 100.000 hectares da terra cultivada entre 1961 a 2012.

A ampliação da fronteira agrícola da quinoa no Altiplano Sul (contexto do estudo) foi impulsionada pela alta demanda dos mercados nacionais e internacionais que pressionaram para corresponder aos produtores do cereal em grandes quantidades de volumes e rendimentos. Também pelo aumento da sobrevalorização dos preços os produtores do grão procuraram terras de fácil acesso às maquinarias, ou seja, as planícies. Pois, tradicionalmente a quinoa era cultivada nas montanhas e ladeiras por um sistema manual e familiar. O cultivo era realizado em cavidades

\footnotetext{
${ }^{7}$ Segundo Benavides (2005), um quintal, em unidade de medida na Bolívia, equivale a 48,6 Kg.
} 
separados lateral e longitudinalmente a um metro, e a uma profundidade de 30 a 35 centímetros para alcançar a umidade do solo (MEDRANO e TORRICO, 2015, p. 30).

Os preços tiveram um aumento vertiginoso, e a pesquisa do Centro de Estudos para o Desenvolvimento Laboral e Agrário - CEDLA (2013) afirma que, por tonelada métrica (Tm) da quinoa os preços praticamente quintuplicaram, entre o período de 1976 a 2012, passando de uma média de \$US 545 para \$US 3.061 no período 2009-2012, acompanhado pelo aumento das áreas cultivadas.

Nos últimos anos a produção vem aumentando, e o objetivo dos atravessadores é a exportação. Mais recentemente, em dezembro de 2018, segundo informações do diretor do Centro Internacional da Quinoa (CIQ) ao site dialogochino.net ${ }^{8}$, a Bolívia enviou 40 toneladas do produto para a China. Já em abril de 2019, esse volume ampliou para 590 toneladas, ou seja, 14 vezes mais em apenas 4 meses.

No ano 2013 a campanha da quinoa no contexto internacional foi favorecida a escalar posições em função da declaração do Ano Internacional da Quinoa pela Assembleia Geral da FAO, com intuito de potencializar alimentos tradicionais e estratégicos para a segurança alimentar e nutricional da humanidade em diversas regiões do mundo, e com o intuito de plantar e produzir a quinoa em outros continentes. O presidente da Bolívia, Juan Evo Morales Ayma, foi nomeado embaixador da quinoa em nível internacional pela FAO em consideração de a Bolívia ser um dos países andinos com maior produção da quinoa.

Como resultado da campanha da FAO, principalmente, nos países tradicionais andinos produtores da quinoa (Bolívia, Peru, Equador) rapidamente implementaram políticas e tecnologias de estímulo à expansão e aumento das áreas do cultivo visando ampliar os volumes do rendimento da produção. Nesse contexto, segundo dados constantes no site da Câmara de Exportadores da Quinoa e Produtos Orgânicos da Bolívia - CABOLQUI, no auge, até 70.000 agricultores bolivianos ampliaram os investimentos na produção da quinoa. A CABOLQUI estabeleceu-se com intuito de fomentar a industrialização e aproveitar a conjuntura do "boom da quinoa" em nível internacional. Articulou com diferentes setores produtoras do cereal e com a ANAPQUI.

Segundo informações apontadas no site da CABOLQUI, a colheita da quinoa na Bolívia atingiu em 2017, 82.500 toneladas. Em 2016 esse número foi de 75.000 toneladas. Do total das exportações da quinoa boliviana, 60\% é destinada aos mercados dos Estados Unidos e Canadá e 25\% para a Europa; o restante para outros países da América Latina, Ásia e Oriente Médio.

\footnotetext{
${ }^{8}$ https://dialogochino.net/pt-br/agricultura-pt-br/26442-china-e-maior-esperanca-da-quinoa-boliviana/
} 
Outro fator de aceleração do desenvolvimento agrícola da quinoa, principalmente a 'quinoa real' da Bolívia, ocorreu com a finlaidade de agregar mais valor a produtos orgânicos e a expandir-se por mecanismos de marketing em diferentes lugares do mundo. Considerando, até o ano de 2008, 90 \% das exportações oficiais eram orgânicas, fazendo da Bolívia o líder mundial em exportação orgânica da quinoa, conforme Aroni, et al. (2009, S/p.).

Do mesmo modo, isto se dá em um contexto onde há uma mudança geral nos padrões de consumo, especialmente nos países com melhores rendas econômicas onde existe uma maior tendência crescente a consumir alimentos saudáveis, nutritivos e com inocuidade garantida e que dedicam tempo às compras, leem as etiquetas e conhecem bem o tipo de alimento que consomem e as caraterísticas especiais adicionais como sua produção orgânica e/ou comércio justo são igualmente requeridas (SCHNEIDER, 2014, p. 11. PACHECO; BLAJOS; ROJAS, 2015, p. 222).

Segundo um dos técnicos da Associação, entrevistado para a presente pesquisa, a ANAPQUI tem aproximadamente 150.000 quintais de quinoa orgânica e certificada. Anualmente chega-se a produzir em torno de 65.000 toneladas. Informou que atualmente são 234 comunidades associadas à ANAPQUI; o equivalente a 2.200 famílias, sendo a organização maior e mais representativa do Altiplano Sul da Bolívia. A associação conta com assistentes técnicos e agrônomos, que se dedicam a realizar visitas técnicas nas comunidades. O produtor associado passa por um processo de certificação orgânica da quinoa, que vai desde a preparação da terra até a colheita e armazenagem. Nesse sentido, com o intuito de consolidar e garantir o produto final de qualidade de seus associados para o mercado, a associação avalia o processo por meio de seus recursos próprios.

\section{Região Pesquisada: Características e Informações Relevante do Município Salinas de Garci Mendoza (Salinas)}

A área do estudo da presente pesquisa é a comunidade ancestral "Salinas" (Figuras 1 e 2), lugar destacado na produção da quinoa real, na conjuntura atual. Os primeiros assentamentos nessas regiões datam de 5.000 anos, configurado pelos povos originários “quechuas" e "aymaras", que predominam até os dias atuais, habitando nas veredas dos grandes Salares de Uyuni, Coipasa e Pastos Grandes, que fazem de um lugar inefável e de paisagens icônicas do Altiplano. 
Figura 1. Ruinas dos Primeiros Assentamentos

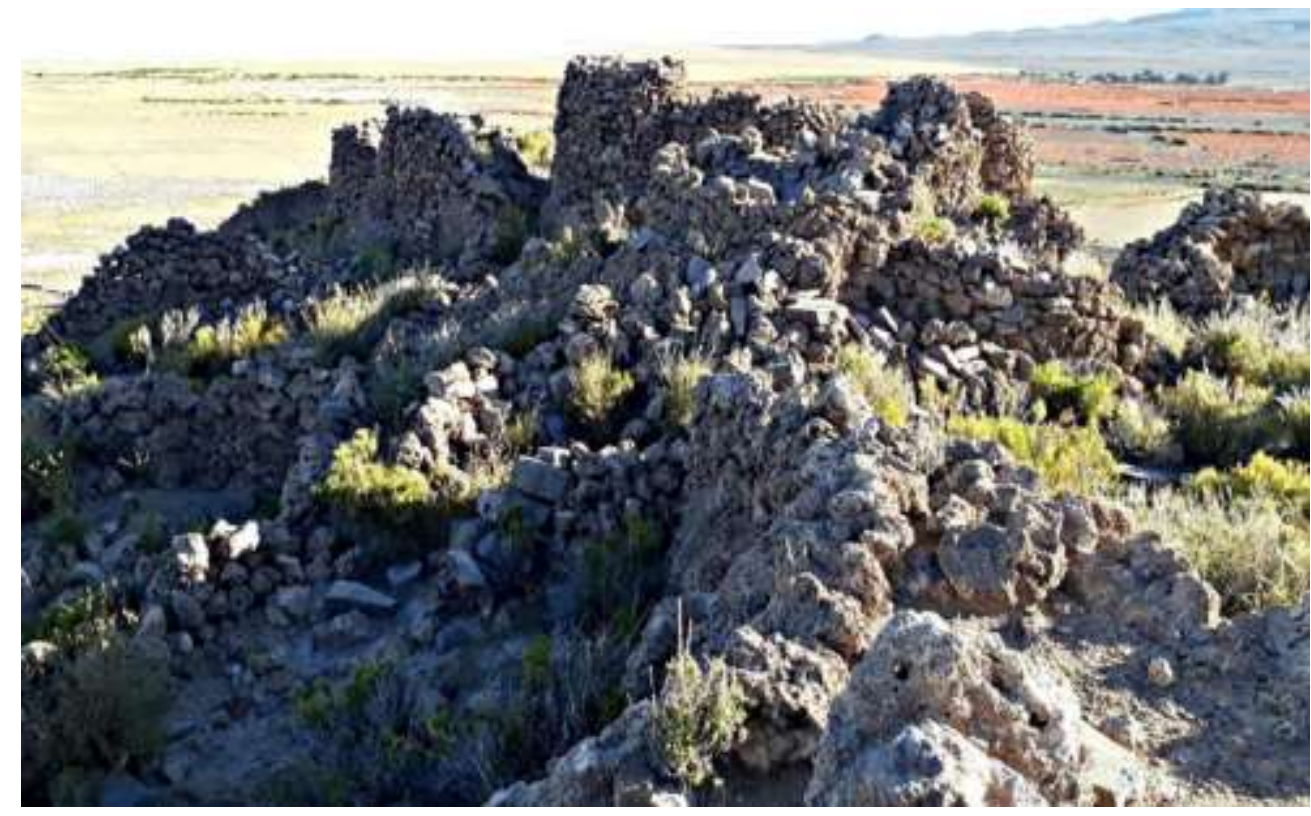

Fonte: LAURA, B. C. Pesquisa de campo, Salinas de Garci Mendoza, 2018. *Prédios construídos 5000 anos atrás pelos primeiros assentamentos dos povos originários e atualmente ruinas em desaparecimento.

Figura 2 - Ruinas dos Primeiros Assentamentos com Salar de Uyumi ao fundo

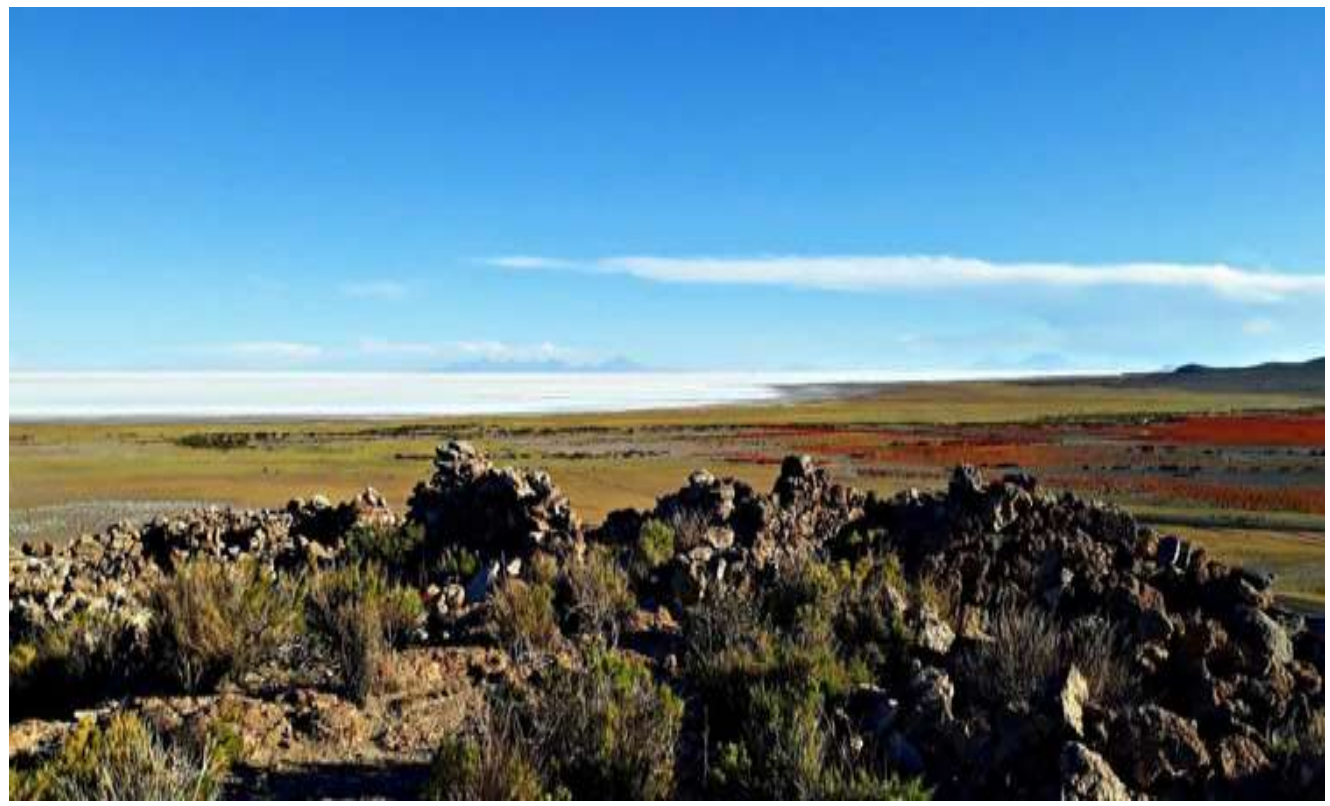

Fonte: LAURA, B. C. Pesquisa de campo, Salinas de Garci Mendoza, 2018. No contorno observa-se o Salar de Uyuni (divisa entre o departamento de Oruro e Potosí) e plantações da quinoa real.

Conforme entrevistas realizadas com atores da comunidade, existe pouca informação sobre os modos da vida dos povos que desapareceram e viveram nessas regiões e as incógnitas ainda prevalecem. Mas as principais atividades desenvolvidas foram a agricultura, pesca e criação de 
gados. Na agricultura seriam os primeiros em selecionar alimentos que conseguissem adaptar-se a solos salinos, cereais-grãos (“Quinoa real”, "Kañihua real”) e tubérculos (diversidade de batatas).

Analisando, os povos destas regiões do Altiplano conseguiram se adaptar e se destacar na produção de determinados alimentos, mantendo os conhecimentos e saberes para um aproveitamento ecoeficiente da biodiversidade. Forjou-se um sistema de agrobiodiversidade com milhares de variedades de batatas (Solanum tuberosum), milhares de variedades de quinoa (Chenopodium quinoa) e também as variedades de Kañihua (Chenopodium pallidicaule) que são atualmente conhecidos mundialmente, segundo Vargas, et al. (2015, p. 82). Naquela época, grande parte dessa produção era de consumo local das famílias e principal fonte alimentar das comunidades do Altiplano.

Os conhecimentos dos modos da vida e organização dos “ayllus" (que significa 'comunidade' no idioma indígena Aymara), povos milenares, foram transcendendo das práticas e costumes que herdaram e passaram de geração a geração via oral. Sabedorias e princípios que ainda primam pela plena transformação das sociedades pela pós- modernidade do século XXI, uma realidade contrastante no município Salinas, atravessada na transformação agrária pela plantação da quinoa real. Tal fato influenciou imediatamente nos modos tradicionais da segurança e soberania alimentar, sendo a quinoa real o alimento principal das comunidades originarias da região.

\section{Contexto Territorial, Social, Econômico do município Salinas}

O Município Salinas de Garcí Mendoza, conhecido como Salinas, situa-se no Altiplano Sul da Bolívia, no departamento (Estado) de Oruro. O departamento é uma região rica em recursos minerais. A mineração da região representa um papel importante desde a colônia e até hoje em dia como um setor fortemente influente na economia do país. Erigido ao pé das colinas San Pedro e San Pablo, no entanto, a referência mais importante da região é o vulcão Thunupa (Figura 3) que fica ao lado do Salar de Uyuni (PRENSA SENADO, 2018). No departamento de Oruro, o município Salinas de Garcí Mendoza e o município de Pampa Aullagas compõem a Província de Ladislao Cabrera. 
Figura 3. Vulcão Sagrado de Thunupa

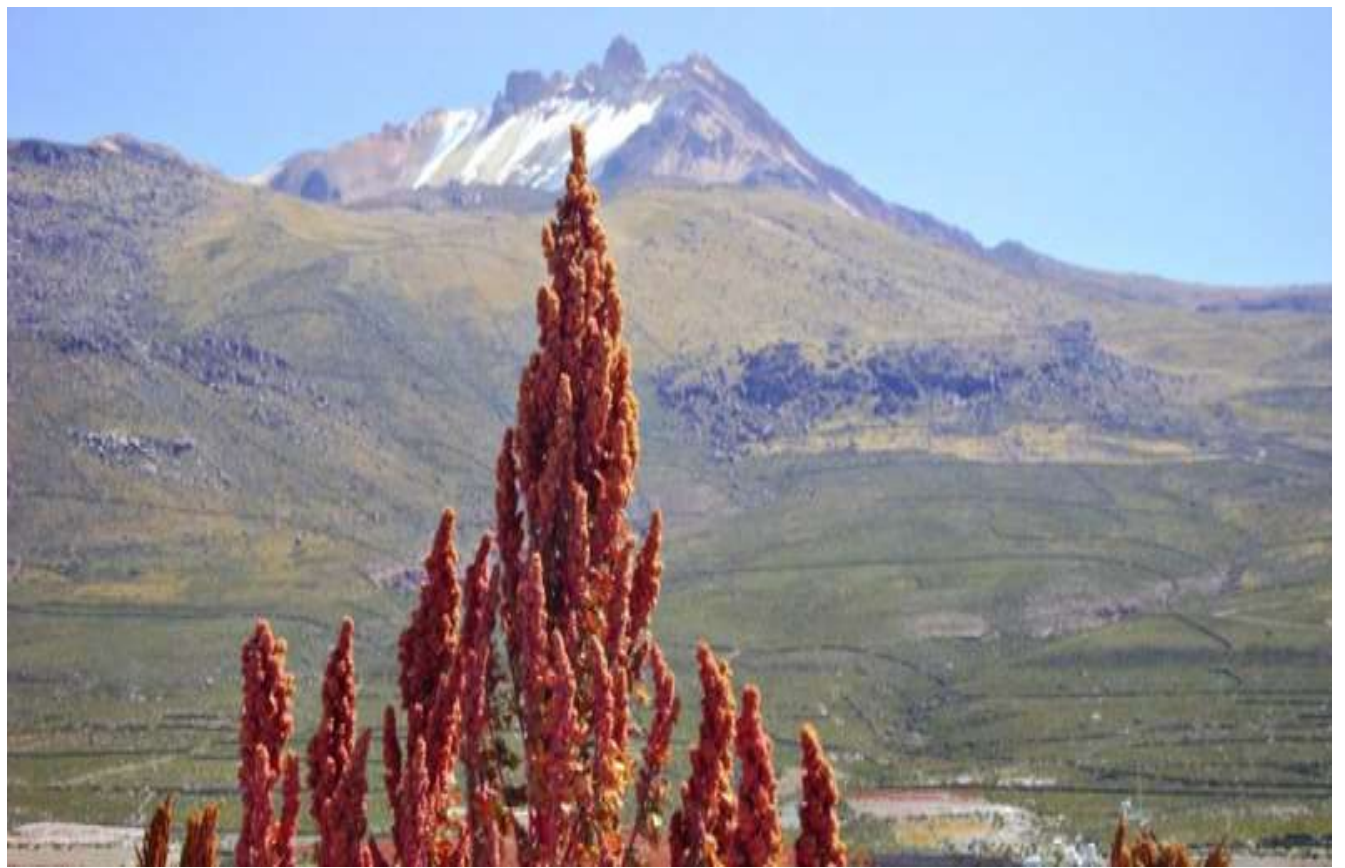

Fonte: LAURA, B. C. Pesquisa de Campo, 2018. *Vulcão sagrado das comunidades indígenas e camponesas do município Salinas de Garci Mendoza.

Salinas é uma região meramente rural, com uma população de aproximadamente 11.705 habitantes, segundo o último censo efetuado em nível nacional em 2012 pelo Instituto Nacional de Estadística. Conforme a mesma pesquisa para 2004, contava com 2.500 famílias, sendo aproximadamente 5.013 homens e 5.036 mulheres. Atualmente as famílias que moram de forma permanente nas comunidades de Salinas são compostas em sua maioria de adultos e, ou, pessoas acima de 60 anos.

A forma da organização administrativa e política é arraigada em práticas ancestrais e se sustenta na estrutura de autoridades originárias e indígenas. Segundo Metais (2011, p. 139), Salinas é composta por cinco "markas" (territórios, em idioma indígena Aymara): Marka Salinas, Marka Uqumasi, Marka Aroma, Marka Challacota Belém e Marka Pajcha San Martín.

Em conversa com produtores e representantes "Jilaqata e Mama Jilaqata, da Marka Salinas, durante a pesquisa de campo, as informações repassadas foram de que o "Jilaqata" de "ayllu” junto com "Mama Jilaqata" propiciam costumes e práticas" culturais e ritos cerimoniais. Os papéis e funções das autoridades são legitimados por meio de um costume ancestral chamado "muyt'a" (rotação temporário e anual), atividade intimamente relacionada ao controle da produção

\footnotetext{
9 "Jilaqata" é autoridade altamente compreendida na vida social da comunidade. Antigamente era autoridade exercida particularmente pelos homens e casados, atualmente exercem os não casados e mulheres, no caso das mulheres denomina-se "Mama Jilaqata.
} 
e manutenção do equilíbrio social na comunidade, portanto, define uma relação com o uso da terra e do território e intervindo na regulação do uso de recursos naturais e na solução de problemas. Esta atividade consiste em um evento realizado pelas autoridades originárias que percorre por todas as comunidades que integram o ayllu, visitando cada família e informando sobre a situação dos trabalhos agrícolas, os conflitos que atravessam e as expectativas do ciclo agrícola e pastoril. Também são atores principais na organização das festividades e atividades rituais das comunidades, sempre em agradecimento da Pachamama ("Mae Terra”) como máxima divindade sagrada.

Esses representantes atuam como guardiões da cultura e da tradição, o que segundo Lima; Neto; Farias (2016, p.72) é crucial na contemporaneidade, pois os guradiões auxiliam na compreensão da necessidade de equilibrar mudanças e permanências: "as memórias são continuamente reproduzidas por esses guardiães que lhes conferem um modo de continuidade das experiências. Eles se tornam ainda mais importantes no mundo contemporâneo para que as experiências passadas, erros e acertos, não se percam da sociedade”.

A organização rural do município de Salinas é baseada na propriedade comunal, porque não teve, nem há, presença das grandes fazendas; Desde a colonização do "novo mundo" a coroa espanhola não conseguiu atingir todas as vastas regiões do altiplano por apresentar cenários pouco atraentes no setor mineiro e agrícola, e que permitiu, de certa forma, manter uma organização estrutural homogênea da comunidade, após a queda da coroa espanhola e ao longo dos governos republicanos e militares.

\section{Aspectos Ambientais, Agroecológicos e Pecuários}

O Altiplano representa uma porção do território nacional, formado pela grande cordilheira dos Andes que atravessa a Bolívia com suas duas ramificações: a cordilheira da Região Ocidental ou vulcânica e a Cordilheira Oriental, que encerram o altiplano Boliviano e volta a se juntar ao sul, formando um grande maciço montanhoso, de acordo com Andressen L., et al. (2007, apud Montes de Oca, 1989).

É importante mencionar que a região do Altiplano, na Bolívia, encontra-se situada em diferentes sub-regiões que influenciam os modos de produção agrícola e nos aspectos abióticos. “O altiplano boliviano ocupa uma área de 178.662 km2 (16,4\% do território nacional); não é uma planície plana, mas é sulcado por várias áreas montanhosas' (ANDRESSEN L. et al, 2007, p. 13). 
O Altiplano Sul, objeto da presente pesquisa situa-se no sudoeste da Bolívia, o clima é classificado de semiárido com frios extremos de inverno, as precipitações pluviais são quase inexistentes entre as estações de outono, inverno e primavera, a época com maior precipitação do ano é o verão. O município de Salinas, com uma extensão de 4,875 km2, compreende a mesma condição climática do Altiplano Sul.

Nas comunidades do município Salinas a pecuária é representada em números maiores pelas lhamas que sobrevivem em áreas ou propriedades de uso coletivo, mas o número de ovelhas é muito mais baixo e é controlado em áreas coletivas e, basicamente, em propriedades individuaisfamiliares.

Tradicionalmente alternava-se o cultivo de quinoa com a pecuária de camelídios, diversificando desta forma sistemas de subsistência e subministrando adubo como fertilizantes para as parcelas da quinoa. Nos últimos anos, devido ao aumento do preço da quinoa, em muitas áreas se registraram uma tendência em favor do cultivo da quinoa e à custa do gado (SCHNEIDER, 2014, p. 26).

Para fomentar uma soberania e segurança alimentar nutritiva, variada e integrada, as comunidades costumavam trocar os produtos da quinoa e batatas, tradicionais da região andina, por produtos produzidos nas regiões tropicais do país, desde verduras, frutas, cereais (principalmente o milho). "Todavia, naquela época, os transportes de mercadorias eram efetuados unicamente em lombo de lhamas ou pelos homens" (MAZOYER e ROUDART, 2010).

Portanto, além da produção para autoconsumo uma parte do excedente da quinoa e batata eram destinadas à troca de produtos alimentares trazidos da região tropical e comercializadas na feira da comunidade. Até hoje em dia os produtos produzidos e nativos da região tropical ainda são ofertados na feira do município de Salinas, mas já não mais em base de troca de produto a produto, mas sim, por moeda.

\section{Flora e Fauna Silvestre}

Entre os animais mais comuns entre os silvestres figuram a vicunha (Vicugna vicugna), o flamenco andino (Phoenicopterus andinua), o gato andino (Felis jacobita), a coruja (Pulsatix glacidium), a lebre (Lepus capense) e a viscacha (Lagidium visclaccla) (SCHNEIDER, 2014, p. 23).

O cenário dos ecossistemas silvestres na região de Salinas do Altiplano Sul é variante, principalmente conformado pelas principais pradarias nativas de "Suputula" "nakatola", "taratola" 
(Parastrephia/as), entre outros, no entanto todos são conhecidos comumente como "Tola"10. Trata-se de um arbusto que é fonte alimentar importante para os camelídios (Lhama, Alpaca, Vicunha, Guanaco) e para as ovelhas. Para os solos salinos e degradados, ela aumenta matéria orgânica e conserva umidade do solo. Os arbustos de "tolares" (Figura 4) cumpriam uma função fundamental para proteção dos solos e cultivos, uma das práticas era estabelecer barreira com finalidade de proteger o solo da erosão e criar um microclima, era uma combinação que permitia criar maior umidade para o solo (ALZÉRRECA, et al., 2002, p. 19).

\section{Figura 4 - Tolares no Altiplano Sul}

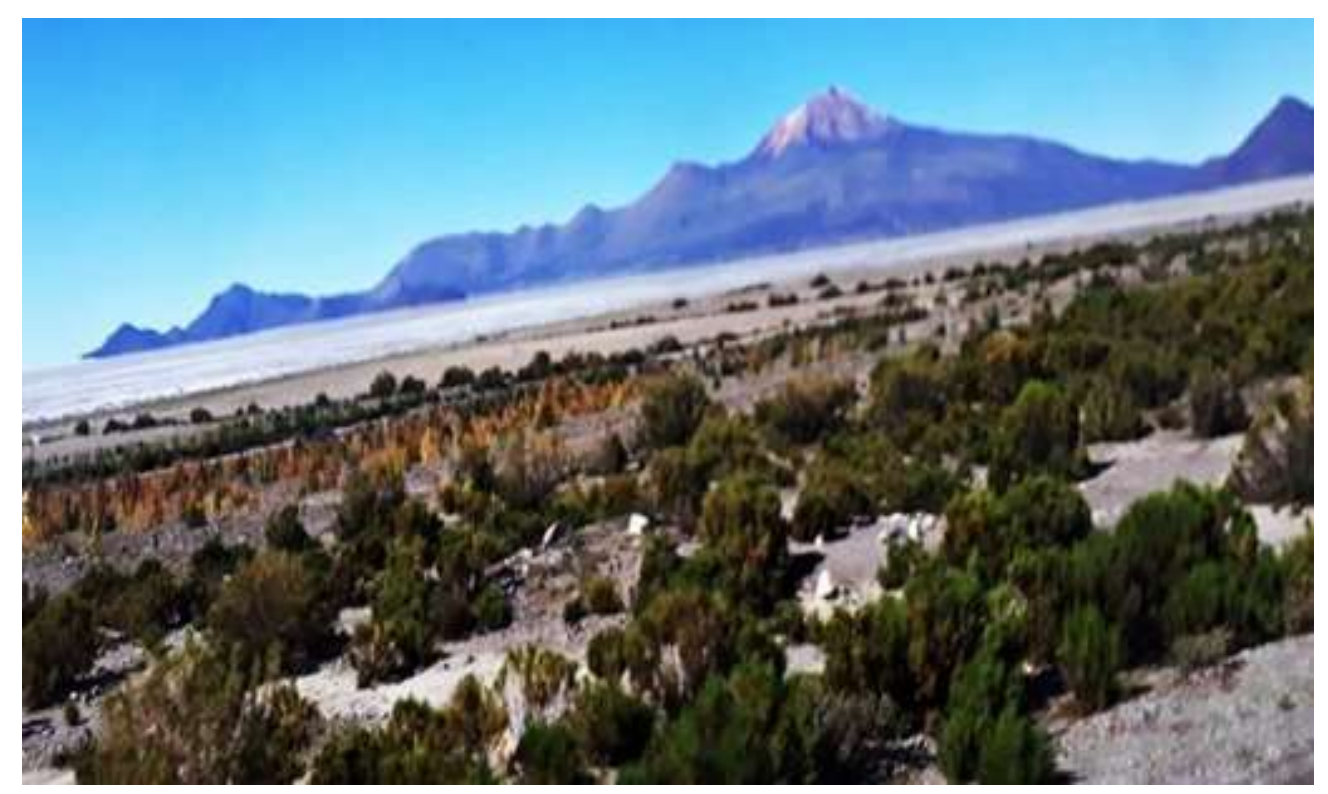

Fonte: LAURA, B. C. Pesquisa de campo, 2018. *Tolares. No horizonte contempla-se o vulcão sagrado de Thunupa, Salinas de Garcí Mendoza.

Não obstante a importância dos tolares, muitas áreas foram arrasadas pelo plantio do grão e foram ficando cada vez mais susceptíveis à degradação e às mudanças climáticas. Tudo em função do desenvolvimento do monocultivo da quinoa real. Tal situação leva a questionar sobre até que ponto será viável, futuramente, o modelo atual da produção da quinoa, considerando o comprometimento na segurança e soberania alimentar da região.

\footnotetext{
${ }^{10}$ Encontrado no texto de ALZÉRRECA, et al. (2002), está o debate do tema dos “Tolares", tanto nas variedades e a importância que representa sócio ambientalmente, na ecologia e flora andina.
} 


\section{Resultados da pesquisa em Salinas}

\section{Mudanças ocorridas no sistema produtivo}

No Município Salinas de Garcí de Mendoza (Salinas), situado no Altiplano Sul da Bolívia, as transformações no modo de fazer agricultura suscitam na reforma da área produzida e na classificação dos sistemas de produção influenciados na especialização, neste caso a agricultura extensiva da quinoa real, nas áreas de planícies onde antigamente eram destinadas a pastoreio dos camelídios e pradaria de plantas silvestres.

A especialização foi aniquilando a diversificação produtiva agrícola e a criação de camelídios como mecanismo de desenvolvimento agrícola e modernização na comunidade. O ecossistema agrícola da quinoa real entra no modo elementar, homogêneo e extensivo; pois, nos últimos anos, a especialização produtiva do cereal é amparada na monocultura e no uso de insumos externos, como explicado pelo entrevistado 3, camponês:

Como a ANAPQUI exige que seus membros produzam quinoa orgânica, então, para atender a essa demanda procuramos empresas que fabricam fertilizantes orgânicos, agora importados do país vizinho Chile, para vender a produtores da quinoa aqui no Altiplano Sul. Nós tivemos bons resultados com este fertilizante orgânico, os produtores incrementaram a demanda pelo adubo orgânico industrial (Entrevistado 3 - produtor, pesquisa de campo, 2018, tradução da pesquisadora).

Nas comunidades produtoras, a partir do momento em que o cenário da quinoa real tornou-se atrativo economicamente pressionou os produtores do cereal a se inserirem na dependência tecnológica (maquinários), na busca de melhoramento genético, mão de obra contratada, procura de novas terras de alcance para maquinário (planícies) e para tornar mais competitivo os rendimentos da produção do cereal e, assim, satisfazer a demanda do mercado nacional e estrangeiro.

Do mesmo modo, a especialização do cereal não só induziu a ampliação dos lugares destinados ao cultivo, assim como promoveu a construção de plantas de industrialização, processamento e transformação do cereal. No Altiplano Sul as organizações atuantes para coordenar e orientar a atividade são associações, como a ANAPQUI e a APQUISA, cuja intenção é a de fortalecer o setor produtivo da quinoa, procurar melhorias tecnológicas, maior acesso a mercados, entre outros.

Um dos fatos verificados nas comunidades pesquisadas é o deslocamento do cultivo da quinoa real para as planícies nas comunidades de Salinas que chega a atingir quase cem por cento. As mudanças ocorreram de um sistema tradicional a não tradicional, conforme depoimento de um técnico da ANAPQUI: 
Nos últimos 30 anos, em Salinas região de maior produção da quinoa real orgânica do Altiplano Sul, tem havido uma inquietante mudança de manejos e sistemas tradicionais para sistemas não tradicionais produtivos. Concordamos que trabalhamos na área técnica da produção da quinoa, que existe um trator, que há máquinas, equipamentos, mas o que não conseguimos controlar são as mudanças antrópicas, muitos lugares já não possuem pradarias naturais e a demanda da quinoa continua crescendo a cada ano. Quando começou a incrementar as áreas produtivas da quinoa, os tolares que são uma fonte importante no ecossistema da região foram destruídos com a pelo uso do trator, a tendência é a extinção destes tolares, principalmente onde estão as plantações da quinoa que não deixa lugar para os tolares que são importantes na biomassa dos solos (Entrevistado 1 - técnico da ANAPQUI, pesquisa de campo, 2018, tradução da pesquisadora).

As políticas voltadas para o desenvolvimento rural na comunidade indígena de Salinas desde a década de 1980 sustentam-se no discurso geral da modernização da agricultura da quinoa, consequentemente originando mudanças repentinas no ambiente agrário, deparando-se atualmente na consolidação produtiva do monocultivo da quinoa, dado que, os resultados econômicos da quinoa fizeram com que o produtor (camponês-indígena) dedique e se especialize exclusivamente na quinoa, deixando de lado muitos conhecimentos e saberes técnicos tradicionais e locais das organizações territoriais nos "ayllus". Recapitulando:

Antes do boom da produção da quinoa, nas comunidades do Altiplano Sul, predominava a combinação de usufruto individual-familiar de pequenas extensões de terra dedicadas à agricultura, com o usufruto coletivo de vastas extensões de terras comunais de pastagens para o gado. Nas parcelas familiares, assentadas fundamentalmente nas partes baixas das ladeiras das montanhas, se produzia quinoa e batata em pequena escala. $\mathrm{O}$ cultivo de quinoa era basicamente destinado ao autoconsumo, enquanto a produção de batata era destinada em parte ao autoconsumo e em parte ao mercado constituído pela população mineradora da região (ORMACHEA e RAMIREZ, 2013, p. 51; LAGUNA, 2000, p. 06).

Os riscos implicados nesta situação é a de perda de um importantíssimo significado cultural e alimentar presente na reprodução social e econômica desses camponeses-indígenas. Além de uma provável transformação no seu sistema social alimentar, riscos esses diretamente relacionados aos princípios de segurança e soberania alimentar e desenvolvimento rural sustentável.

Anterior ao chamado boom e abrangência da atividade econômica da quinoa, o sistema agrário foi caracterizado pela gestão coletiva do espaço e recursos. O território comunal era dividido entre dois a quatro "mantas" ou "aynoqas" (áreas) de aproveitamento. Todos os anos a comunidade decidia o cultivo de uma "manta" ou "aynoqa" (área), deixando o resto em repouso (Metais, 2011). Este sistema consistia em um conjunto de parcelas com controle coletivo sincronizado (LAGUNA, 2000, p. 06).

O sistema de "aynoqas" foi uma herança dos nossos antepassados e avôs que deixaram legados e conhecimento importantes, por exemplo, o trabalho agrícola por mantas (propriedades de produção), onde os camelídios eram distribuídos 
para pastoreio e em quanto dispersam adubo para próxima plantação de culturas. Mas hoje em dia ninguém quase pratica isso, também não há mais terra para essa pratica de trabalho em mantas, pois a plantação da quinoa ficou nas planícies e continua ocupando as poucas terras que ficam (Entrevista com uma Autoridade Originaria de Marka Salinas, pesquisa de campo, 2018, tradução da pesquisadora).

Conforme depoimentos dos produtores e autoridades representantes de Salinas, a especialização da quinoa influiu imediatamente no usufruto familiar e individual das terras nas planícies, conjuntamente trouxe graves conflitos na posse da terra entre as comunidades, gerando a desigualdade no usufruto da terra. O conflito pela terra ainda fica prevalecente nas comunidades, principalmente entre famílias que ainda procuraram título de propriedade em vista das áreas limitadas e poucas terras disponíveis.

\section{Perspectiva Econômica}

De modo geral os produtores na comunidade dependem quase que totalmente dos recursos financeiros advindos da produção da quinoa, constituindo-se uma das principais atividades econômicas, principalmente das famílias que moram de forma permanente na comunidade. Por outro lado, estão produtores chamados "residentes" que contam com terras na comunidade e frequentam só por temporadas do plantio e produção da quinoa, ou participação de reuniões e algum evento cultural e ritual que ainda prevalece na comunidade. Os "residentes" moram principalmente nos grandes centros urbanos e maiormente dependem de outras atividades econômicas (prestação de serviços, professores, comerciantes, entre outros) além da quinoa. “O número das famílias produtoras que moram de forma permanente na comunidade é baixo, vinte cinco por cento (25\%), já os 'residentes' representam setenta e cinco por cento (75\%)" (Entrevistado 1, técnico ANAPQUI, pesquisa de campo, 2018).

Também a entrevistada 6, camponesa, nascida na comunidade, de 47 anos, casada e mãe de dois filhos, expressa que, "existiam produtores permanentes que elaboravam manualmente alimentos artesanais e típicos da quinoa (sopa da quinoa, massas, farinha, entre outros) para a comercialização na feira da comunidade, mas que hoje é quase inexistente". Pois, atualmente, a preferência é destinar o total do grão bruto ao setor agroindustrial das associações de ANAPQUI e APQUISA que atua na transformação industrializadora e que interage com as grandes cadeias de empresas que tornam mais competitivo o produto final no mercado local quanto para exportação.

As transformações do cenário produtivo da quinoa em Salinas não se trata de um novo rural no sentido encontrado em Carneiro (1998 e 2005), Brandemburg (2010) e Wanderley (1996), 
citados por Lima (2016), como um rural que não necessitaria, obrigatoriamente, a se manter estático ou preso ao passado, mas que se adapta às transformações, a algumas mudanças de forma crítica e sem colocar em risco a cultura local e o saber tradicional dos camponeses.

\section{Contexto alimentar}

Diferentes estudos e pesquisas afirmam ser a Quinoa um alimento primordial das presentes e futuras gerações. Em vista disso, organismos relevantes como a FAO ratificam um alimento de vital importância para a segurança com soberania alimentar, sendo um grão que consegue adaptar-se em variados pisos ecológicos e, na maior parte dos casos, não depende de precipitações pluviais ou irrigação. Difundir os grandes benefícios nutritivos da quinoa foi ficando paulatinamente popular em diferentes lugares do mundo.

No contexto local da presente pesquisa, os produtores compreendem os benefícios gerados economicamente, mas, em termo alimentar existe a falta de informação constante dos grandes benefícios na saúde, são poucos que reconhecem o grão com um alimento de riquíssimos valores nutricionais e de proteínas. O país é considerado como o segundo maior comercializador da quinoa a mercados internacionais, depois do Peru, mas o uso comestível interno continua sendo reduzido e limitado quando comparado a outros produtos alimentares.

Os dados do Centro Internacional da Quinoa (CIQ), na Bolívia em 2018 atingiuse $2.31 \%$ per capita, em 2013 o consumo foi de $1.21 \mathrm{~kg}$ de consumo per capita, 2014 subiu para 1.76, 2015 para 1.90, 2016 para $2.09 \mathrm{~kg}$ e 2017 para 2.41 consumo per capita. [...] A tendência tem sido de aumentar o consumo por ano em nível nacional (AGENCIA BOLIVIANA DE INFORMAÇÃO - ABI, 2019, $\mathrm{S} / \mathrm{p})$.

Durante a pesquisa, em busca nos dados de 2017, do Centro Internacional da Quinoa (CIQ) e Instituto Nacional de Estadística (INE), foi possível levantar informações sobre o consumo anual de quinoa na Bolívia, que era em torno de $1,4 \mathrm{Kg}$ per capita , muito baixo para um alimento tradicional da cultura local, e sobretudo, quando comparado a outros alimentos, como a batata (99 $\mathrm{Kg})$, arroz $(32 \mathrm{Kg})$, macarrão e pão $(58 \mathrm{Kg})$, tomate $(6 \mathrm{Kg})$, cenoura $(2,4 \mathrm{Kg})$, açúcar $(39 \mathrm{~kg})$, milho $(12 \mathrm{Kg})$, frango $(44 \mathrm{Kg})$, carne bovina $(21 \mathrm{Kg})$, carne suína $(8.5 \mathrm{Kg})$. Verifica-se que a quinoa era o menos consumido de acordo com os dados de 2017.

No entanto, o aumento no valor do preço do grão é uma variante que se choca com outros alimentos e que interfere no processo de escolha para consumo. Nos últimos anos, o preço do grão subiu consideravelmente e o consumidor local não consegue mais comprar a um preço justo e acessível como antes. Para o ano 2019, um quilograma de arroz e macarrão chegou a custar cinco 
bolivianos (USD 0.72), em contraste ao custo da quinoa que chega a dezesseis bolivianos (USD 2.3), no mesmo ano.

Desta maneira, os consumidores mais afetados são, em grande maioria, os que não têm condições e recursos econômicos para comprar a quinoa e, assim, deixam de fora da sua dieta, optando por consumir alimentos bem menos econômicos e de fácil acesso, porém, de qualidades nutritivas limitadas. Portanto, encarar a quinoa como um alimento e produto estratégico para atuar na segurança com soberania alimentar no país e na comunidade local é ainda ineficiente e questionável, já que isso por sí só não soluciona o problema da população local que mais sofre com a insegurança alimentar e nutricional.

Não obstante, não se conseguiu obter dados definitivos em relação à redução do consumo da quinoa na comunidade pesquisada comparado ao consumo antes do boom econômico, por não haver dados oficiais relacionados a essa situação especificamente para Salinas, mas as entrevistas permitiram constatar que houve uma grande redução do consumo do grão nos últimos anos também no local.

Em salinas historicamente a quinoa real foi a base da alimentação e da cultura culinária da comunidade. Por intermédio das conversas e desde uma perspectiva empírica na vivencia, foi possível constatar que, muitas famílias que moram e produzem a quinoa trocaram a base da sua alimentação por produtos envasadas e ultraprocessadas e de fácil acesso. Também, a mudança do hábito de consumir o grão suscita no sistema produtivo e influencia bastante o seu preço. Outros aspectos reparados que estariam interferindo na mudança dos hábitos alimentares é a maior integração dos meios de comunicação que universalizam e fazem publicidade para promover outros produtos industrializados que, em muitos casos, não contam com a mesma qualidade nutricional da quinoa. Outro fator diz respeito às feiras e feirantes no município que proporcionam para a venda local maiormente produtos processados e industrializados (em muitos casos bem mais econômicos e importados) e a oferta de produtos locais como a quinoa ou derivados é pouco ofertada.

Os 'residentes" ${ }^{11}$ voltam à comunidade em diferentes temporadas (preparo do solo, plantio, colheita, entre outros) e também são atores que levam novas opções de produtos

\footnotetext{
11 "No final da década de 1970, as regiões do Altiplano Sul sofreram uma situação angustiante, houve uma seca forte e dramático, que fez a perca da produção e não existia possibilidades de fazer uma agricultura eficiente, também a seca afetou nos vertedouros das águas para consumo das famílias. [...] Uma conjuntura que provocou o grande êxodo rural do altiplano para outras regiões do país e no estrangeiro, em busca de melhores oportunidades de vida. As terras foram abandonas ou em muitos casos arrendados e deixados para cuidar a famílias que ficavam e mantiveram a permanência. Mas quando a quinoa foi integrada para o processo da industrialização, a demanda da produção também foi incrementada, especificamente nos últimos anos. Dado isso, os migrantes, que são denominados "residentes", que deixaram as terras voltaram para solicitar e exigir o direito das suas propriedades para as autoridades originarias dos 'ayllus' e das famílias que ficaram com as terras. As terras abandonas, por meio do consenso dos ayllus, procederam
} 
alimentares, pois são famílias que moram principalmente nas cidades e têm outros hábitos culinários globalizados. Além do que, os residentes pouco compreendem a quinoa como estratégia de soberania e segurança alimentar para a comunidade. O principal interesse dos 'residentes' é o lucro fornecido pelo cultivo e colheita do grão, e aproveitar a conjuntura do boom econômico do cereal.

Neste processo, as práticas alimentares foram mudando drasticamente, pois o único alimento produzido com destino à comercialização é a quinoa, abandonando os produtos andinos como a batata, canhihua, oca, fava, outros, que décadas atrás eram produzidos para variar e equilibrar a dieta da alimentação local. Também se constata a perda de receitas culinárias preparadas à base da quinoa, como dito por uma camponesa: "Eu prefiro destinar o total da produção bruta à associação e comprar o produto final já envasado, pois manipular a quinoa em casa para consumir leva tempo, é melhor comprar da loja" (Entrevistada 7 - Pesquisa de Campo, 2018, tradução da pesquisadora). Por conseguinte, na comunidade o consumo de alimentos baseados na quinoa vai sendo reduzido e trocado por outros produtos alimentares com altos índices de carboidratos de fácil acesso e preparação, os que mais se observaram no consumo cotidiano das famílias está a farinha branca, açúcar, arroz, macarrão, óleo, entre outros. Assim, se evidencia a alteração do modo do consumo alimentar pelos produtos industrializados-globalizados e que contam com preços menores.

\section{Contexto de Políticas Setoriais}

Nestes últimos anos, foram numerosas políticas voltadas para o setor agropecuária e de segurança e soberania alimentar no País. Os principais organismos foram incentivando desde diferentes políticas nacionais para motivar aos produtores e fortaleceram a difusão da quinoa no mercado. Também as políticas setoriais para a produção alimentar partem desde uma perspectiva do "bem viver" e de conexão harmônica com a natureza e 'mãe terra'. Portanto, a quinoa como produto estratégico foi constantemente colocado e mencionado nas políticas planejadas. As políticas orientadas para a segurança alimentar com soberania também consideram a quinoa como uma solução à fome e à pobreza local e do País.

para apropriação das famílias permanentes que trabalham e cumprem o papel social e econômico que exige a comunidade. Ainda assim, essas famílias que migraram entraram com outros processos legais e não respeitaram mais o consenso das comunidades e isso gerou outro problema pela terra nestas comunidades do Altiplano Sul (Entrevista com um produtor e autoridade originaria de Salinas, pesquisa de campo, 2018, tradução da pesquisadora). 
Quadro 1. Políticas Orientadas à Quinoa

\section{Principais Politicas da Quinoa}

* A Lei $\mathrm{n}^{\circ} 98$ (2011) declara a produção uma prioridade nacional, industrialização e comercialização de quinoa em regiões produtoras do país.

* A Lei no 395 e o Decreto Supremo no 1927 (2014) constituem e regulamentam o Centro Internacional de Quinoa com Sede na Bolívia.

* A Lei $n^{\circ} 144$ (2011) da Revolução Produtiva identifica a quinoa como produto estratégico dentro do Plano de Produção de Alimentos.

* A Política Nacional de Quinoa (2009) é promulgada dentro dos diretrizes do Plano Nacional de Desenvolvimento, definindo a geração de Complexos Produtivos Integrais com objetivos de inovação tecnológica, uso sustentável dos recursos naturais, comércio, créditos, infraestrutura institucional e produtiva.

* Lei no 300 (2013) da Mãe Terra e Bem Viver tem dentro de seus 25 postulados que "saber comer" é saber combinar os alimentos certos a partir das estações do ano.

Fonte: LAURA, B. C. Elaboração própria em base a dados de NOGALES et al. (2015).

No contexto pesquisado, existe uma série de controvérsias na execução e, em concretizar as leis e políticas estabelecidas. A prática agrícola de monocultivo e inserção de maquinaria agrícola sem controle, incremento do preço, baixo consumo do grão local e nacional, preocupação central em satisfazer o mercado estrangeiro, perda de consenso comunitário, produção convencional e não orgânica da quinoa, entre outros, estão alheios e distantes de atingir uma produção de base racional com o meio ambiente e que assevere a soberania e segurança alimentar.

Por outro lado, estão os atores importantes - lideranças indígenas camponesas - que em grande medida possuem uma grande representação na tomada de decisões da comunidade e têm articulado para avançar na implementação das políticas de segurança com soberania alimentar, partindo desde o processo da produção agrícola, implementação de tecnologias e, fundamentalmente, no melhoramento de consenso entre o setor comunitário, público e privado, 
que procurem priorizar e assegurar a quinoa como alimento de preço justo e de acesso para toda a população.

É evidente a desigualdade social e econômica na comunidade de Salinas, partindo desde a concentração da terra que reflete a realidade de cada produtor. No entanto, diferentes depoimentos de produtores e técnicos concordam que a quinoa também trouxe benefícios econômicos e melhoria de condições de vida para a comunidade, usando como justificativa que o local apresenta um cenário inviável para uma agricultura diversificada, o que faz com que a quinoa seja uma oportunidade de gerar renda.

\section{Considerações finais}

A pesquisa demostrou alguns efeitos da intervenção do novo modelo produtivo da quinoa na segurança e soberania alimentar em nível local. Constatou-se que, desde a década de 1970, quando começou o interesse produtivo e econômico pela quinoa real na comunidade de Salinas houve uma mudança drástica na forma de produção agrícola, pois até essa década os produtores plantavam quinoa fundamentalmente para autoconsumo. Também o cultivo da quinoa se dava nas montanhas combinado com a rotação de outros cultivos como a kanhihua, oca, diversidade de batatas, favas, entre outros; que atualmente despareceram, além de que, o total da plantação da quinoa foi trasladada às planícies pela implementação de maquinaria agrícola que não consegue chegar ao alto das montanhas. Essa mudança transformou a produção de multicultivo a monocultivo da quinoa. Também causando impactos nos sistemas ecossistêmicos.

Houve uma mudança geral no consumo de alimentos diversificados produzidos na comunidade. Pois muitos produtores se especializaram em produzir unicamente a quinoa e começaram a transferir o total da produção ao mercado e às associações como ANAPQUI e APQUISA responsáveis por destinar ao mercado nacional e, sobretudo, ao mercado estrangeiro, tanto a quinoa quanto produtos derivados, industrializados. A divulgação dos ricos valores nutricionais da quinoa, nos últimos anos, é uma evidência que se contempla nas publicidades.

Aliado a esse processo está a redução drástica do seu consumo pela população local, incluindo agricultores, com o objetivo de destinar toda a produção para a comercialização, priorizando assim, a renda obtida com a quinoa em detrimento de seu valor cultural alimentar e valor nutricional. Mesmo os habitantes da cidade, deixaram de consumi-lo em função do aumento no valor dos preços de mercado à população interna. Portanto, em nível local e nacional a quinoa passou a um preço elevado comparado a outros alimentos de consumo cotidiano. As famílias de baixos recursos econômicos foram as mais afetadas. 
Outro dado importante é que a grande maioria que está presente na comunidade é composta por atores 'residentes' que moram em outros lugares e, principalmente, nos centros urbanos e se deslocam à comunidade para unicamente produzir quinoa e aproveitar a conjuntura do boom econômico do grão. Esse grupo em questão, habitantes sazonais e de área urbana, não tem a quinoa como cultura alimentar de peso na dieta, pois possuem como padrão alimentar o consumo baseado em alimentos processados e ultraprocessados, o que difere da cultura e história alimentar da população local, autóctone.

Da quinoa se falou muito, e as políticas nacionais também orientaram o olhar para este setor como um alimento de estratégia para a segurança com soberania alimentar, tanto nacional como mundial, pois foi comprovado que o grão é apto para diferentes solos ecológicos, tanto é, que muitos países estão optando por cultivar e produzir este alimento.

$\mathrm{Na}$ comunidade as políticas voltadas para a quinoa como futuro da segurança alimentar precisa ainda ser trabalhada, também nesse marco os atores responsáveis devem introduzir ações concretas para um uso sustentável dos recursos que se geraram até a atualidade.

Também existe uma sinalização clara de redução do consumo da quinoa no País em função de seu valor comercial e isso é um aspecto extremamente importante para serem abordados em estudos de pesquisa e extensão, sobretudo no que se refere à perda da soberania alimentar e da segurança alimentar atrelada à cultura produtiva e de consumo. É preciso observar que o custo do produto para a população local precisa ser acessível e o produto de qualidade, considerando, ainda, o seu alto poder nutritivo.

A transformação ocorrida no território de Salinas, em função da expansão e especialização da quinoa, em detrimento da diversificação alimentar antes existente entre os camponeses, aponta para um contexto que não pode ser considerado como sendo de um desenvolvimento rural sustentável, haja vista a desconexão com as práticas alimentares tradicionais do local, numa região onde a quinoa tem uma raiz cultural milenar. Tais transformações, que agora ocorrem, chegam a interferir rapidamente no consumo alimentar, transformando a quinoa em apenas um produto a ser comercializado, embora como estratégia de marketing - o que pode ser observado em embalagens do produto comercializados em outros países - se utilize da importância cultural deste alimento na região andina, ao passo que tal alimento tem sofrido forte impacto no que se refere ao consumo pelos próprios bolivianos, principalmente os de baixa renda, e inclusive, por aqueles que cultivam o cereal.

Com o presente estudo buscou-se trazer discussão que venha a contribuir no conjunto com outras pesquisas, já desenvolvidas e as que virão, sobre a realidade vivenciada na comunidade ancestral de Salinas em relação a produção da quinoa real e os impactos socioprodutivos e de 
segurança e soberania alimentar. Trata-se também de um aporte aos temas que estão em curso sobre o Desenvolvimento Rural Sustentável na América Latina.

\section{Agradecimentos}

À Coordenação de Aperfeiçoamento de Pessoal de Nível Superior - CAPES pela bolsa do estudo. Aos participantes da pesquisa em Salinas de Garci de Mendoza.

\section{Referências}

AGENCIA BOLIVIANA DE INFORMACION (ABI). Bolivia incrementa su consumo per cápita de quinua a 2,31 kilogramos. 2019. Disponível: 〈https://www1.abi.bo/abi_/?i=419949>. Acesso em: 20 Maio 2019.

ALZÉRRECA, Humberto A; CALLE, Porfirio M.; LAURA, Jorge C. Manual de Manejo y Uso Sostenible de los Tolas e los Tolares. La Paz. 2002. Disponível: <http://www.altperubolivia.org/Web_Bio/PROYECTO/Docum_bolivia/21.07\%20manual.pdf> Acesso em: 18 jan. 2019.

ANDRESSEN L. Rigoberto; MONASTERIO, Maximina; TERCEROS, Luis F. Regímenes climáticos del altiplano sur de Bolivia: una región afectada por la desertificación. Vol. 48(1). Revista Geográfica Venezolana. 2007. p. 11-32.

ARIÑEZ, Rubén. Bolivia elige a la alemana ACI Systems para industrializar el litio; se proyecta ganancia anual de \$us 1.000 MM. La Razón, 20/04/2018. Disponível em: https://eju.tv/2018/04/bolivia-elige-a-la-alemana-aci-systems-para-industrializar-el-litio-seproyecta-ganancia-anual-de-us-1-000-mm/ Acesso em: 06 jun. 2019.

ARONI, Juan C.; CAYOJA, María; LAIME, Marco A. Situación actual al 2008 de la quinua real en el Altiplano Sur de Bolivia. Oruro: FAUTAPO. 2009.

BENAVIDES, Zina A. Cáceres. Quinoa: a tradição frente ao desafio dos novos mercados de qualidade. 2005. 301 f. Tese (Doutorado em Ciência em Desenvolvimento, Agricultura e Sociedade) - CPDA, UFRJ, Rio de Janeiro, RJ, 2005.

Bioversity International, FAO, PROINPA, INIAF and IFAD. 2013. Descriptors for quinoa (Chenopodium quinoa Willd.) and wild relatives. Bioversity International, Rome, Italy; Fundación PROINPA, La Paz, Bolivia; Instituto Nacional de Innovación Agropecuaria y Forestal, La Paz, Bolivia; International Fund for Agricultural Development, Food and Agriculture Organization of the United Nations, Rome, Italy. Disponível em: https://www.bioversityinternational.org/fileadmin/user_upload/online_library/publications/pdfs/ 
Descriptors_for_quinoa_Chenopodium_quinoa_Willd_and_wild_relatives_1679.pdf Acesso em: 22 jan. 2019.

BRANDENBURG, Alfio. Do rural tradicional ao rural socioambiental. Ambiente \& Sociedade, Campinas, v. 13, n. 2, p. 417- 428, jul./dez. 2010.

CABOLQUI (Cámara Boliviana de Exportadores da Quinoa y Productos Orgánicos). Año Internacional de la Quinua 2013. S/d. Disponivel em: https://cabolqui.org/?v=72df28bd206a

Acesso em: Fev. 2019.

CARNEIRO, Maria José. Ruralidades: novas identidades em construção. Estudos Sociedade e Agricultura, n. 11, p. 53-75, out. 1998.

Identidades sociais: ruralidades no Brasil contemporâneo. Apresentação. In: MOREIRA, Roberto José; CARNEIRO, Maria José et al. (Orgs). Identidades sociais: ruralidades no Brasil contemporâneo. Rio de Janeiro: DP\&A, 2005. p. 7-14.

CARDOZO, Armando. Crianza y produccion de camelidos en Bolivia. United States Aid Mission to Bolivia. La Paz: 1985. Disponível em: https://pt.scribd.com/document/392501733/Datos-de-camelidos-1985-pdf Acesso em 25 fev. 2019.

CEDLA - Centro de Estudios para el Desarollo Laboral y Agrario. Cultivo de la quinua y producción capitalista en las comunidades del Altiplano sur de Bolivia. Boletín de Seguimiento a Políticas Públicas, n. 22. Julho, 2013. Disponível em: https://cedla.org/publicaciones/prya/control-ciudadano-22-cultivo-de-la-quinua-y-produccioncapitalista-en-las-comunidades-del-altiplano-sur-de-bolivia/ Acesso em: 22 jan. 2019.

DELGADO B. Freddy; DELGADO Á, Mayra. El vivir y comer bien en los Andes Bolivianos: Aportes de los sistemas agroalimentarios y las estrategias de vida de las naciones indígena originario campesinas a las políticas de seguridad y soberanía alimentaria. La Paz: Agruco. 2014.

Disponível

em:

http://biblioteca.clacso.edu.ar/Bolivia/agruco/20170927034706/pdf_357.pdf Acesso em: 25 jan. 2019.

BOJANIC, Alan. La Quinua: Cultivo milenario para contribuir a la seguridad alimentaria mundial. Oficina Regional para America Latina y el Caribe. FAO - PRINPA. Julio, 2011. Disponível em:

https://www.academia.edu/32600735/La_quinua_Cultivo_milenario_para_contribuir_a_la_segur idad_alimentaria mundial\#: :text=La\%20quinua\%3A\%20Cultivo\%20milenario\%20para,contrib uir\%20a\%201a\%20seguridad\%20alimentaria\%20mundial Acesso em: 24 jan. 2019.

FELIX, Dorian. Culture durable du quinoa en Bolivie: pratiques individuelles et règles communautaires. Culture durable du quinoa en Bolivie - ASVF. VSF-CICDA - RURALTER, 
Lyon: RURALTER. France, 2008. Disponível em: https://www.avsf.org/public/posts/567/culturedurable-du-quinoa-en-bolivie-pratiques-individuelles-et-normes-communautaires.pdf Acesso em: 20 nov. 2019.

LAGUNA, Pablo. El impacto del desarrollo del mercado de la quinua en los sistemas productivos y modos de vida del altiplano sur boliviano. Sistematización de la experiencia de inserción al mercado de la quinua. La Pa: ANAPQUI. 2000.

LIMA, Romilda de S.; NETO, José. A. Ferreira; FARIAS, Rita de C. Pereira. Dinâmicas alimentares na relação rural-urbano o caminho entre o tradicional e o moderno In: PRADO, Shirley D., et al. (Orgs). Estudos socioculturais em alimentação e saúde: saberes em rede. Rio de Janeiro: EDUERJ, 2016. Sabor metrópole series, vol. 5, pp. 59-79. Disponível em: http://books.scielo.org/id/37nz2/pdf/prado-9788575114568-04.pdf Acessado em: 10 jul. 2020.

MAZOYER, Marcel; ROUDART, Laurence. História das agriculturas no mundo: do neolítico à crise contemporânea. São Paulo: Editora UNESP; Brasília, DF: NEAD, 2010.

METAIS, Sarah. La vivencia de Salinas, en el altiplano sur de Bolivia. In: MORALES, Miguel (Org.). Hablemos de tierras Minifundio, gestión territorial, bosques e impuesto agrario en Bolivia. La Paz: Editorial Plural, 2011. p. 139-153.

MONTES DE OCA, I. Geografía y recursos naturales de Bolivia. La Paz: Editorial Educacional, 1989.

MORÓN, Cecilio. Importancia de los cultivos andinos en la seguridad alimentaria y nutricion. In: FAO - Cultivos Andinos. Livro 7, cap. 3. Disponível em: http://www.fao.org/tempref/GI/Reserved/FTP_FaoRlc/old/prior/segalim/prodalim/prodveg/cdro m/contenido/libro07/Cap3 3.htm\#3 Acesso em: 20 mar. 2020.

MUJICA, A. IZQUIERDO, J. MARATHEE, J-P. Origen y descripcion de la quinua. In: MUJICA, A. Et al. Quinua (Chenopodium quinoa willd) - Ancestral cultivo andino, alimente del presente y futuro. FAO - Cultivos Andinos. 2001. Disponível em: http://www.fao.org/tempref/GI/Reserved/FTP_FaoRlc/old/prior/segalim/prodalim/prodveg/cdro m/contenido/libro03/home03.htm Acesso em 19 set. 2020.

NOGALES, Maria T.; THELLAECHE, Javier; SILVA, Gabriela. Quinua y el Altiplano Sur: producción y seguridad alimentaria. La Paz: Fundación Alternativas, 2015.

ORMACHEA, Enrique S.; RAMIREZ, Nilton F. Propiedad colectiva de la tierra y producción agrícola capitalista: el caso de la quinua en el Altiplano Sur de Bolivia. La Paz: CEDLA, 2013.

PACHECO, Mauricio; BLAJOS, Jorge; ROJAS, Wilfredo (Orgs.). Características del consumo y los mercados. In: RISI, Juan; ROJAS, Wilfredo; PACHECO, Mauricio. Producción y mercado de la quinua en Bolivia. La Paz: IICA 2015, p. 211-264.

PRENSA SENADO BOLIVIA. Municipio de Salinas de Garci Mendoza celebra sus 77 años de creación. Política, 23, mar, 2018. La Paz: Prensa Senado. Disponível em: https://web.senado.gob.bo/prensa/noticias/municipio-de-salinas-de-garci-mendoza-celebra-sus77-a\%C3\%B1os-de 
creaci\%C3\%B3n\#: :text=La\%20C\%C3\%A1mara\%20de\%20Senadores\%20aprob\%C3\%B3,en \%20el\%20desarrollo\%20del\%20Estado Acesso em: 11 nov. 2018.

RISI, Juan; ROJAS, Wilfredro; PACHECO, Mauricio. Producción y mercado de la quinua en Bolivia. La Paz: IICA, 2015.

SCHNEIDER, Melanie M. Análisis de la cadena de valor de la quinua (chenopodium quinoa willd) en Bolivia. Dissertação de Mestrado. 2004. 131 f. Dissertação (Mestrado em Ciências Ambientais) - PMPCA, Universidad Autónoma de San Luis Potosí, San Luis Potosi, 2014.

SILVA, F.V.; SOUZA, V. M.; GULARTE, M. A. Pseudocereais e suas características. In: SBCTA-RS, $5^{\circ}$ Simpósio de Segurança Alimentar, Alimentação e Saúde. Anais. Bento Gonçalves, RS, 2015, p.1-4. Disponível em: http://www.ufrgs.br/sbctarseventos/gerenciador/painel/trabalhosversaofinal/SAL130.pdf Acesso em: 06 jul. 2019.

VARGAS, Dani E. H.; BODADA, Marti; ARRACA; Lenny; et al. Agrobiodiversidad y economía de la quinua (Chenopodium quinoa) en comunidades aymaras de la cuenca del Titicaca. Idesia, Arica, v. 33, n. 4. p. 81-87, nov. 2015. Disponível em: https://scielo.conicyt.cl/scielo.php?script=sci_arttext\&pid=S0718-34292015000400011 Acesso em: 18 abr. 2019.

WANDERLEY, Maria N. Baudel. Raízes históricas do campesinato brasileiro. In: ENCONTRO ANUAL DA ANPOCS, 20, 1996, Caxambu, MG. Anais. Texto 5, p. 1-18, Out. 1996. Disponível em: https://wp.ufpel.edu.br/leaa/files/2014/06/Texto-5.pdf Acesso em: 30 set. 2020.

Recebido em: 12/09/2020 Aprovado em 10/122021 